\title{
The Sapir-Whorf Hypothesis Today
}

\author{
Basel Al-Sheikh Hussein \\ Department of English Language and Literature, Al-Zaytoonah Private University of Jordan, Amman, Jordan \\ Email: ibrashihab@yahoo.com
}

\begin{abstract}
The Sapir-Whorf's Linguistic Relativity Hypothesis provokes intellectual discussion about the strong impact language has on our perception of the world around us. This paper intends to enliven the still open questions raised by this hypothesis. This is done by considering some of Sapir's, Whorf's, and other scholar's works.
\end{abstract}

Index Terms - perception, language, thought.

\section{INTRODUCTION}

Needless to say that the "Linguistic Relativity Hypothesis", well-known as the Sapir-Whorf Hypothesis, has been the subject of controversy ever since it was first formulated. Its originator was the American anthologist and linguist E.Sapir. He clearly expresses the principle of this hypothesis in his essay "The Status of Linguistics as a science "(cf. Sapir, selected Essays, 1961). B.L. Whorf reformulated the hypothesis in his 1940 published essay "Science and Linguistics" (cf. Whorf, Selected Writings, 1956).

The Sapir-Whorf hypothesis proclaimed the influence of language on thought and perception. This, in turn, implies that the speakers of different languages think and perceive reality in different ways and that each language has its own world view. The issues this hypothesis raised not only pertain to the field of linguistics but also had a bearing on Psychology, Ethnology, Anthropology, Sociology, Philosophy, as well as on the natural sciences. For, if reality is perceived and structured by the language we speak, the existence of an objective world becomes questionable, and the scientific knowledge we may obtain is bound to be subjective. Such a principle of relativity then becomes a principle of determinism. Whether the language we speak totally determines our attitude towards reality or whether we are merely influenced by its inherent world view remains a topic of heated discussion.

In this paper, the author only intends to enliven the already started discussion of the still unanswered questions raised by this hypothesis. However, a short general background as to the real initiators of the Linguistic Relativity Hypothesis is inevitable.

\section{GERMANS AS THE INITIATORS OF THE LINGUISTIC RELATIVITy HypothESIS}

Sapir and Whorf were by no means the initiators of the notion of linguistic relativity. The idea that the language system shapes the thinking of its speakers was first formulated by the German philosophers J.G. Herder (1744-1803) and W.V. Humboldt (1767-1835). However, it was Humboldt's philosophy of language that influenced linguistics. He felt that the subject matter of linguistics should reveal the role of language in forming ideas. That is to say, if language forms ideas, it also plays a role in shaping the attitudes of individuals. Hence, individuals speaking different languages must have different world views.

\section{SAPIR'S AND WHORF’S VIEWS ON LANGUAGE}

\section{A. Sapir}

For Sapir, language does not reflect reality but actually shapes it to a large extent. Thus, he recognizes the objective nature of reality; but since the perception of reality is influenced by our linguistic habits, it follows that language plays an active role in the process of cognition. Sapir's linguistic relativity hypothesis can be stated as follows:

a) The language we speak and think in shapes the way we perceive the world.

b) The existence of the various language systems implies that the people who think in these different languages must perceive the world differently.

The idea that a given language shapes reality resembles Humboldt's idea of the world view inherent in every language. Sapir was acquainted with Humboldt's views, but his ideas on the role of language in the process of cognition were not genetically linked with Humboldt's opinions. Sapir reflections on language were based on empirically verifiable data resulting from his own work on American Indian languages.

Sapir realized that there is a close relationship between language and culture so that the one cannot be understood and appreciated without knowledge of the other. Sapir's views on the relationship between language and culture are clearly expressed in the following passage taken from his book "Language". 
"Human beings do not live in the objective world alone, nor alone in the world of social activity as ordinarily understood, but are very much at the mercy of the particular language which has become the medium of expression for their society. It is quite an illusion to imagine that one adjusts to reality essentially without the use of language and that language is merely an incidental means of solving specific problems of communication or reflection. The fact of the matter is that the 'real world' is to a large extent unconsciously built up on the language habits of the group... We see and hear and otherwise experience very largely as we do because the language habits of our community predispose certain choices of interpretation." (Sapir, 1929b, P.207).

\section{B. Whorf}

The formulation of the linguistic relativity, for which Whorf is famous, was the result of his prolonged study of the Hopi language (an American Indian language). His first attempts at interpreting the Hopi grammar according to the usual indo-European categories were abandoned when they produced unexplainable irregularities. The linguistic structures that he found were very different from those of his mother tongue, English. Whorf argues that this implies a different way of thinking. Since thought is expressed through language, it follows that a differently structured language must pattern thought along its lines, thus influencing perception. Consequently, a Hopi speaker who perceives the world through the medium of his language must see reality accordingly.

Whorf's formulation of the linguistic relativity hypothesis is more radical than Sapir's but it is the one that is referred to as the Sapir-Whorf hypothesis. This hypothesis is not homogeneous as its name would indicate.

Sapir did not doubt the existence of an objective world. He said that human beings do not live in the objective world alone, but that the real world is, to a large extent, unconsciously built up on the language habits of the group.

Whorf stated that the world is presented in a kaleidoscopic flux of impressions which has to be organized by the linguistic system in our minds. This would seem to make the objective world into something totally subjective for Whorf.

Whorf extended his master's (Sapir's)ideas, and went much further than saying that there was a 'predisposition' ; in Whorf's view, the relationship between language and culture was a deterministic one.

The strongest Whorf statement concerning his ideas is the following:

"The background linguistic system (in other words, the grammar) of each language is not merely a reproducing instrument for voicing ideas but rather is itself the shaper of ideas, the program and guide for the individual's mental activity, for his analysis of impressions, for his synthesis of his mental stock in trade. Formulation of ideas is not an independent process, strictly rational in the old sense, but is part of a particular grammar, and differs, from slightly to greatly, between different grammars. We dissect nature along lines laid down by our native languages. The categories and types that we isolate from the world of phenomena we do not find there because they stare every observer in the face; on the contrary, the world is presented in a kaleidoscopic flux of impressions which has to be organized by our minds - and this means largely by the linguistic systems in our minds. We cut nature up, organize it into concepts, and ascribe significances as we do, largely because we are parties to an agreement to organize it in this way - an agreement that holds throughout our speech community and is codified in the patterns of our language. The agreement is, of course, an implicit and unstated one, but its terms are absolutely obligatory; we cannot talk at all except by subscribing to the organization and classification of data which the agreement decrees."(Carroll, 1956, pp.212-14).

Even though Whorf's view in the above quotation is a deterministic one, he does not claim that a language completely determines the world-view of its speakers; he states that "This fact [the close relationship between language and its speakers, world-view] is very significant for modern science, for it means that no individual is free to describe nature with absolute impartiality but is constrained to certain modes of interpretation even while he thinks himself most free. The person most nearly free in such respects would be a linguist familiar with very many widely different linguistic systems. As yet no linguist is in such position. We are thus introduced to a new principle of relativity, which holds that all observers are not led by the same physical evidence to the same picture of the universe, unless their linguistic backgrounds are similar, or can in some way be calibrated (Carroll, 1956, p. 214).

Different speakers, then, view the world differently, and even sophisticated linguists aware of structural differences between languages cannot see the world as it is without the screen of language. Fishman (1960 and 19752 c) considered the kinds of claims the Sapir-Whorf hypothesis makes. Among these claims is that, if speakers of one language have certain words to describe things and speakers of another language lack similar words, then speakers of the first language will find it easier to talk about those things. This is the case if we consider the technical terms used in different sciences; for instance, physicians talk easily about medical phenomena, more than anyone else. A stronger claim is that, if one language makes distinctions that another does not make, then those who use the first language will more readily perceive the differences in their environment which such linguistic distinctions draw attention to. If you must classify 'camels', differently from someone who is not asked to make these distinctions.

The application of Whorf's views to the area of grammar makes his claims stronger, since classification systems that belong to sex, number, time, are both more subtle and more pervasive. The effect of such grammatical systems is stronger on language users than vocabulary differences alone. The strongest claim of all is that the grammatical categories available in a particular language not only help the users of that language to perceive the world in a certain way but also at the same time limit such perception. You perceive only what your language allows you, or predispose 
you, to perceive. Your language controls your world- view. Speakers of different languages will, therefore, have different world-views.

Whorf acquired his views about the relationship between language and the world through his work as a fire prevention engineer, and through his work, as Sapir's student, on American Indian languages, especially on the Hopi language of New Mexico. Whorf found through his work as a fire prevention engineer that English speakers used the words 'full' and 'empty' in describing gasoline drums in relation to their liquid content alone; so, they smoked beside 'empty' gasoline drums, which weren't actually 'empty' but 'full' of gas vapor. Whorf was led by this and other examples to the conclusion that "The cue to a certain line of behavior is often given by the analogies of the linguistic formula in which the situation is spoken of, and by which to some degree it is analyzed, classified, and allotted its place in that world which is to a large extent unconsciously built up on the language habits of the group." (Carroll, 1956, P. 137).

The real work that led Whorf to make his strongest claims was his involvement in American Languages, in particular his contrastive studies on the Hopi Indian Language. He contrasted the Hopi linguistic structure with that of English, France, and German. Whorf found that these languages share many structural features that he named 'Standard Average European (SAE). Whorf, then, came to the conclusion that Hopi and SAE differ widely in their structural characteristics For example, Hopi grammatical categories provide a 'process' orientation toward the world, Whereas the categories in SAE give SAE speakers a fixed orientation toward time and space so that they not only 'objectify' reality in certain ways but even distinguish between things that must be counted, e.g., trees, hills, and sparks, and those that need not be counted, e.g., Water, fire, and courage. In SAE 'events occur', 'have occurred', or 'will occur, in a definite time ; i.e., present, past, or future ; to speakers of Hopi, what is important is whether an event can be warranted to have occurred, or to be occurring, or to be expected to occur.

Whorf believed that these differences lead speakers of Hopi and SAE to view the world differently. The Hopi see the world as essentially an ongoing set of processes; objects and events are not discrete and countable; and time is not apportioned into fixed segments so that certain things recur, e.g. , minutes, mornings, and days. In contrast, speakers of SAE regard nearly everything in their world as discrete, measurable, countable, and recurrent; time and space do not flow into each other ; sparks and flames are things like pens and pencils; mornings recur in twenty-four hour cycles, and past, present, and future are every bit as real as sex differences. The different languages have different obligatory grammatical categories so that every time a speaker of Hopi or SAE says something, he or she must make certain observation about how the world is structured because of the structure of the language each speaks.

In this view, then, language provides a screen or filter to reality; it determines how speakers perceive and organize the world around them, both the natural world and the social world. Consequently, the language you speak helps to form your world-view. It defines your experience for you; you do not use it simply to report that experience. It is neutral but gets in the way, imposing habits of both looking and thinking.

Those who find the Whorfian hypothesis attractive argue that the language a person speaks affects that person's relationship to the external world in one or more ways. If language A has a word for a particular concept, then that word makes it easier for speakers of language A to refer to that concept than speakers of language B, who lack such a word and are forced to use a circumlocution. Moreover, it is actually easier for speakers of language A to perceive instances of the concept. If a language requires certain distinctions to be made because of its grammatical system, then the speakers of that language become conscious of the kinds of distinctions that must be referred to ; for example, sex, time, number, and animacy. These kinds of distinctions may also have an effect on how speakers learn to deal with the world, i.e., they can have consequences for both cognitive and cultural development.

Boas (1911) long ago pointed out that there was no necessary connection between language and culture or between language and race. People with very different cultures speak languages with many of the same structural Characteristics, e.g., Hungarians, Finns, and the Samoyeds of northern Siberia; and people who speak languages with very different structures often share much the same culture, e.g., Germans and Hungarians, or many people in southern India, or the widespread Islamic culture. Moreover, we can also dismiss any claim that certain types of languages can be associated with 'advanced' cultures and that others are indicative of cultures that are less advanced. As Sapir himself observed on this last point (1921, p.219) "When it comes to linguistic form, Plato walks with the Macedonian swineherd, Confucius with the head-hunting Savage of Assam".

It might be useful to take a quick look at some of Whorf's essential works and at the way he develops his grammatical method since this has contributed to the understanding of the Hopi language and since the study of the Hopi language lays the groundwork for his formulation of the hypothesis.

\section{Whorf's Essential Works}

In his essays: "A Linguistic Consideration of Thinking in Primitive Communities "(1936, see selected writings. Ed: j.B. carroll. MIT, New York....1956) and "Grammatical Categories " (1937, above source), Whorf draws the attention to the fact that traditional grammar only describes the external formal structure of a language and overlooks the linguistic relations that are not accounted for by sounds. These unmarked internal relations are what Whorf terms "covert categories". As an example, he cited the case of the English gender. Except for the pronouns, HE, SHE, IT, there is no real classification of gender in English, Which does not stop this category from being operative. Names are unmarked for gender, but the native speaker knows whether they refer to a man or a woman, and picks out the appropriate pronoun. 
The "overt categories" are those that are marked by a sound and detected by a written sign.

The Navaho (an American Indian language) classification for objects is a covert one. It classifies different sorts of objects according to attributes like long, round, etc. Whorf refers to them as CRYPTOTYPES, as opposed to the PHENOTYPES with a clear meaning and formal mark. Since CRYTOTYPES are not marked, the speaker is not aware of them.

The presence of CRYPTOTYPES and the fact that we are unaware of their functioning, led Whorf later (Science and Linguistics, 1940) to conclude that thought is patterned by speech and therefore both thinking and speaking are influenced by the grammatical structure of our mother tongue.

In general, Whorf's views on language touch upon the problem of reality and perception, logic and cognition. In his "Language and Logic" (1941), Whorf attempts to demonstrate that common logic is not universal but dependent on the language of the speaker. The average person does not realize the influential nature of linguistic structure on his cognitive processes.

Whorf translated different languages into one another and obtained completely different structures and meanings. Some languages like Nootka (an American Indian language) do not divide their sentences into individual words. Whorf blames the Greeks for building up a contrast system and making it a law of reason, such as: Verb/Subject; Action/Actor, and Subject/Predicate. He says the European languages are built up on this contrast and consequently tend to objectivist phenomena. This "bipartition ideology of nature" common to European languages has influenced modern science in the way they "see actions and forces where it sometimes might be better to see states" (p.244). Therefore, Whorf cautions us not to accept the biased world view of a single language. He insists upon the necessity of analyzing many different language structures in order to correct the provisional analysis of reality and world view that western culture has imposed on modern science. That is to say, to avoid the despotism of language, Whorf proposes that we learn many differently structured languages.

\section{Evaluation of THE ISSUES RAISED By the SAPIR-WHORF HyPOTHESIS}

Apart from Whorf, the study of the Hopi language has been the continuing occupation of the American Team of Linguists, C.C. Voegelin and F.M. Vangelis. Their first concern was the systematization of the Hopi Vocabulary. This was intended to facilitate the classification of the Hopi grammatical categories. That is to say, their approach is a linguistic one; its aim is not primarily to verify Whorf's data in order to prove or disprove the Sapir - Whorf hypothesis. This was done by the German linguists, H. Gipper and E. Malotki. Malotki says that "a different kind of linguistic emphasis leads to a certain kind of linguistic thinking "(1979:301). Gipper is just as cautions. He states that our language does influence our cautious, we grow up and learn its structures unconsciously and we articulate our thoughts according to its grammar. There can be no doubt that our mother tongue influences our thinking process, but since we are capable of initiating changes in our language and in our thinking habits, the question of relativity cannot be posed in terms of absoluteness or determinism, but in terms of degree (cf. 1972).

By restating the problem in terms of degree, it is possible to unite the mirror (Schiff's) theory with the creation theory, which asserts the creation of reality by the medium of language. Doing this would allow the following combination: in the first case, we perceive the existence of an objective reality, but in the second case, as adults, we perceive it out of habit through the medium of our language which structures our impressions and accentuates or disregards certain phenomena. The question is: to what degree does language influence us?

Language also affects our perception: the remembering of color cards by recalling their names; remembering figures according to the label we gave them during perception, etc. Carroll has demonstrated in a test given to Navaho and English speaking children that Navaho children classified objects according to their shapes, thus illustrating how perception can influence cognition. Cognition is also influenced by our linguistic structures.

\section{CONCLUSION}

Whorf may not have been right on all counts, but he was not wrong either. The fact that language plays a role in shaping our thoughts, in modifying our perception and in creating reality is irrefutable. Gipper phrased the question properly when he asked; to what extent does language influence us? In view of the positive (favorable to the hypothesis), or neutral results which the different tests have yielded, it would seem that the question of linguistic relativity is still a subject of controversy today. Although the search for linguistic universals has been intensified, it will be impossible to determine what is universal, if we don't know what is particular. Linguistic forms and grammatical categories need not appear so different, if their functions are similar.

\section{REFERENCES}

[1] Boas, F. (1911). Handbook of American Indian languages. Introduction, Washington; Government Printing House, Part I, PP.583.

[2] Bright, j.O. and Bright, W. (1965). Semantic Structures in Northwestern California and the Sapir - Whorf Hypothesis, American Anthropologist 67, No. k, part 2, pp. 249-258.

[3] Brown, R.1. (1967). Wilhelm von Humboldt's conception of Linguistic Relativity. The Hague/Paris: Mouton. 
[4] Buehler, k. (1978). Sprachtheorie. Die Darstellungsfunktion der sprache. Frankfurt/Berlin/Wien: Ullstein.

[5] Carroll, J.B. (ed.) (1956). Language, Thought, and Reality: Selected writings of Benjamin Lee Whorf. Cambridge, Mass.: MIT Press.

[6] Carroll, J.B. (1964). Language and Thought. Englewood Cliffs (N.Y.): prentice Hall.

[7] Carroll, J.B. (1963). Linguistic Relativity, Contrastive linguistics, and language Learning. International Review of Applied linguistics in Language Teaching I. pp. 1-20.

[8] Chafe, W.L. (ed., 1976). American Indian Languages and American linguistics. Lisse: The Peter de Ridder Press.

[9] Davies, I. (1998). "A Study of Colour Grouping in Three Languages: A Test of Linguistic Relativity Hypothesis." British Journal of Psychology 89 (3):433-453.

[10] Davies, I., P. Sowden and D. Jerrett. (1998) . "A Cross-cultural Study of English and Setswana Speakers on a Colour Triads Task: A Test of the Sapir-Whorf Hypothesis. British Journal of Psychology 89:1-15.

[11] Fearing, F. (1954). An Examination of the conception of Benjamin Whorf in the Light of the Theories of perception and Cognition. In: language in Culture, ed.: h. Hoijer. Chicago: University Press. Pp. 47-78.

[12] Fishman, J.A. (1960). A Systematization of the Whorfian Hypothesis. Behavioral Science, 5:323-39.

[13] Fishman, J.A. (1972 c). The Sociology of Language: An Interdisciplinary Social Science Approach to Language in Society. Rowle, Mass.: Newbury House.

[14] Gipper, h. (1972). Gibt es ein Sprachliches Relativitaets-prinzip? Untersuchungen zur Sapir-Whorf Hypotheses. Frankfurt/Main; S. Fischer.

[15] Hackett, Ch. F. (1954). Chinese versus English. An Exploration of the Whorfian Thesis. Language in culture, ed.; h. Hoijer, Chicago; University Press. Pp. 106-123.

[16] Humboldt, W. von (1607). Ueber die Verschiedenheit des menschlichen Sprachbaues. Gesammelte Schriften, Vol.6, part I. Berlin: B. Bohr's Verlag. Pp. 111-303.

[17] James, H.L. (1956). The Hopi Indians. Their History and Their culture. Caldwell (Idaho): The caxton Printers.

[18] Lee, P. (1997). "Language in Thinking and Learning: Pedagogy and the New Whorfian Framework." Harvard Education Review 67:430-471.

[19] Lenneberg, E.H. (1953). Cognition in Ethnolinguistics. Language 29. pp. 463-471.

[20] Lucy, J. (1997). "Linguistic Relativity."Annual Review of Anthropology 26:291-313.

[21] Malotki, E. (1979). Hopi-Raum. Eine sprachwissenschaftliche Analyse der Raumvorstellungen in der hopi Sprache. Tuebingen ; Gunter Nau Verlag.

[22] Miller, R.L. (1968). The Linguistic Relativity Principle and Humboldtian Ethnoliguistics. A History and Appraisal. The Hague/ Paris: Mouton.

[23] Pinnow, H. j. (1974). Studie zur Verbstammvariation im Navaho. Indiana, Beiheft 2. Berlin; Gebr. Mann, (XIII).

[24] Ross, P.E. (1992). "New Whoof in Whorf: An Old Language Theory Regains its Authority."Scientific American 266(2):24-26.

[25] Sapir, E. (1961). Culture, Language and Personality. Selected Essays. Ed.: david G. Mandelbaum, Berkeley and Los Angeles: University of California Press.

[26] Sapir, E. (1949). Language. An introduction to the Study of Speech, $8^{\text {th }}$ ed., New York; Harcourt, Brace \& Co.

[27] Sapir, E. (1921). Language: An Introduction to the study of speech. New York: Harcourt, Brace.

[28] Sapir, E. (1929 a). Male and Female Forms of speech in Yana. In S.W.J. Teeuwen (ed.), Donum Natalicum Schrijnen. Nijmegen: Dekker \& Van de Vegt.

[29] Sapir, E. (1929 b). The Status of Lingusics as a science, Language, 5: 207-19.

[30] Schaff, A. (1973). Language and Cognition. New York: MCGraw -Hill.

[31] Steinfatt, T. (1989). "Linguistic Reality: Toward a Broader View. "Language, Communication and Culture: Current Directions. Newbury Park, CA: Sage.

[32] Voegelin, Ch. F. and Voegelin, F. M. (1957). Hopi Domains. A Lexical Approach to the Problem of Selection. Supplement to international Journal of American linguistics 23.

[33] Whorf, B.L. (1946). The Hopi Language, Toreva Dialect. Linguistic Structures of Native America, ed.: H. howeer. New York; Viking Fund Publications in Authorpdogy. Pp. 158-183.

[34] Whorf, B.L. (1956). Language, Thought and Reality. Selected Writings. Ed.: J.B. Carroll. MIT, New York: J.Wilky/London: Chapinaon \& Hall.

Basel Al-Sheikh Hussein was born in Burqa/Jordan 1947. He received his MA in Linguistics from Goethe University / W. Germany (1980), whereas PhD degree in Linguistics was received from Goethe University / W. Germany (1985). Over the past 20 years he was teaching linguistics to Arab Students in University of Basrah, Takreet University (Iraq) and in Al-Zaytoonah University, $\mathrm{Al}$-Zarqa University and Al-Isra University (Jordan). Since then, he has been doing research in the field of linguistics, sociolinguistics and applied linguistics. Dr. Basel Al-Sheikh Hussein is currently an Assistant Prof. of English Linguistics, AlZaytoonah University of Jordan / College of Arts / Dept. of English. 